Rios, S., Cristelo, C., Viana da Fonseca, A., Ferreira, C. (2016). Structural Performance of Alkali Activated Soil-Ash versus Soil-Cement. Journal of Materials in Civil Engineering, 28(2),

DOI: 10.1061/(ASCE)MT.1943-5533.0001398

(http://ascelibrary.org/doi/full/10.1061/\%28ASCE\%29MT.1943-5533.0001398)

(c) 2015 American Society of Civil Engineers

\title{
Structural Performance of Alkali-Activated Soil Ash versus Soil Cement
}

\author{
Sara Rios $^{\text {a; }}$ Nuno Cristelo ${ }^{\text {b; }}$ António Viana da Fonseca ${ }^{\text {c }}$; and Cristiana Ferreira ${ }^{\mathrm{d}}$ \\ a Post-Doc Research Fellow (corresponding author), CONSTRUCT-GEO, Faculty of Engineering, University \\ of Porto, Portugal, sara.rios@fe.up.pt \\ ${ }^{\mathrm{b}}$ Assistant Professor, CQVR, School of Science and Technology, University of Trás-os-Montes e Alto Douro \\ 5000-801, Vila Real, Portugal \\ ${ }^{\mathrm{c}}$ Associate Professor, CONSTRUCT, Faculty of Engineering, University of Porto, Rua Dr. Roberto Frias, s/n \\ 4200-465, Porto, Portugal \\ d Assistant Professor, CONSTRUCT, Faculty of Engineering, University of Porto, Rua Dr. Roberto Frias, s/n \\ 4200-465, Porto, Portugal
}

\begin{abstract}
Alkaline activation of fly ash was used to improve the mechanical performance of a silty sand, considering this new material as a replacement of soil-cement applications namely bases and subbases for transportation infrastructures. For that purpose, specimens were molded from mixtures of soil, fly ash and an alkaline activator made from sodium hydroxide and sodium silicate. Uniaxial compression tests showed that strength is highly increased by the addition of this new binder. The results described a high stiffness material, with an initial volume reduction followed by significant dilation. All specimens have clearly reached the respective yield surface during shearing, and peak strength Mohr-Coulomb parameters were defined for each mixture. The evolution of the microstructure during curing, responsible for the mechanical behavior detected in the previous tests, was observed by scanning electron microscopy. These results were compared to soil-cement data obtained previously with the same soil at similar compaction conditions. The main difference between both binders was the curing rate, with alkali activated specimens showing a more progressive and long-lasting strength increase. This was analyzed taking into account the chemical process responsible for the behavior of the mixtures.
\end{abstract}

Keywords: Fly-ash, Alkaline activation, Soil improvement, Strength, Curing rate 


\section{Introduction}

One of the major techniques usually used to overcome the problems created by underperforming soils refers to the use of mixtures with a cementitious binder. Traditionally, these binders are cement and/or lime, which bind the soil particles together through chemical reactions. The production of cement has severe environmental impacts, using vast amounts of fossil fuels and being responsible for the emission of more than $5 \%$ of all the carbon dioxide worldwide (Provis and Deventer, 2014). Hence, the use of increasing amounts of waste as a material source for the construction industry represents a highly significant contribution for the reduction in cement consumption. In this paper, an alternative to cement in soil stabilization applications is proposed, based on the activation of an industrial waste - coal burning fly ash.

Alkaline activation (AA), also known as geopolymerisation when low-calcium precursors are used (Davidovits, 1991), can be described as a reaction between alumina-silicate materials and alkali or alkali-based earth substances, namely: $\mathrm{ROH}, \mathrm{Ca}(\mathrm{OH})_{2}, \mathrm{R}_{2} \mathrm{CO}_{3}, \mathrm{R}_{2} \mathrm{~S}, \mathrm{Na}_{2} \mathrm{SO}_{4}$, $\mathrm{CaSO}_{4} \cdot 2 \mathrm{H}_{2} \mathrm{O}$, R2.(n)SiO2, in which $\mathrm{R}$ represents an alkaline ion, such as sodium $(\mathrm{Na})$ or potassium $(\mathrm{K})$, or an alkaline earth ion, such as calcium $(\mathrm{Ca})$. It is a fairly recent technology (first suggested in the late '70s), which is still in the first stage of its development cycle. Most research works found in the literature are focused not only on the development of new applications, but also on a clearer understanding of the basic mechanisms behind the chemical and physical reactions of this material.

The conceptual model used to describe the reactions mechanism can be summarized in the following sequence: dissolution, precipitation/gelation and crystallization/hardening (Duxson et al., 2007). It starts with the destruction, due to the high hydroxyl (OH-) concentration in the alkaline medium, of the $\mathrm{Si}-\mathrm{O}-\mathrm{Si}, \mathrm{Al}-\mathrm{O}-\mathrm{Al}$ and $\mathrm{Al}-\mathrm{O}-\mathrm{Si}$ covalent bonds present in the vitreous 
phase of the original silica and alumina-rich raw material releasing $\mathrm{Si}$ and $\mathrm{Al}$ ions into the solution. At the same time, the alkaline cations - usually $\mathrm{Na}+$ or $\mathrm{K}+$, depending on the activator used - act as building blocks of the structure, compensating the excess negative charges associated with the modification of the aluminium coordination during the dissolution phase. The resulting products finally precipitate and reorganize into more stable and ordered Si-O-Al and Si-O-Si structures (Fernández-Jiménez et al., 2005a). If calcium is present in the mixture in significant amounts, the dissolved Al-Si complex will diffuse from any solid surface recently formed during the ongoing nucleation process, therefore favoring the production of a dominant $\mathrm{C}-\mathrm{S}-\mathrm{H}$ gel phase. Otherwise, the $\mathrm{Si}$ and $\mathrm{Al}$ ions will be able to accumulate around the nuclei points, sharing all the oxygen ions and forming a $\mathrm{Si}-\mathrm{O}-\mathrm{Al}$ and $\mathrm{Si}-\mathrm{O}-\mathrm{Si}$ three-dimensional structure (the formation of $\mathrm{Al}-\mathrm{O}-\mathrm{Al}$ is not favored). The resulting product is an amorphous alumina-silicate gel, which evolves, with curing time and crystallization, from an Al-rich phase to a Si-rich phase (Fernández-Jiménez et al., 2006a). The crystallization, starting almost immediately after the precipitation, is responsible for the hardening of the gel, which eventually matures into a zeolite. The experimental conditions govern the exact type of zeolite (Fernández-Jiménez and Palomo, 2005b). However, it is not usually possible to characterize the full crystallization stage into a zeolite during the scope of a research project, due to the slow development rate of such process.

Most alumina-silicate substances are crystalline in nature, meaning that these constitute very stable matter, therefore their participation in any chemical reaction is actually very difficult. In order to improve the conditions for its activation, the original raw material should be submitted to a previous thermal treatment. This will induce the loss of constituent water and the recoordination of the aluminium and oxygen ions, transforming the structure from crystalline to amorphous (Davidovits, 1991; Sperinck et al 2011; He et al., 2012). This structural 
modification creates an environment where chemical combinations are easier. For that reason, raw materials with a natural or artificial thermal history, such as fly-ash, blast furnace slag, Portland cement residues, pozzolanic wastes, or metakaolin, are more suitable for alkaline activation than non-calcined materials, like clay or feldspars.

Although using basically the same matter, the alkali-activated structures are more stable than those existing in the original alumina-silicate source, thus forming a polymeric product with significantly more resistance to chemical attacks than cement-based materials. The nature of the chemical reactions behind the formation of cement-based binders consists of calcium and silicon compounds, and this can be considered the main difference between cement and geopolymeric binders: the calcium dependency. Calcium-based binders are known to have a relatively poor resistance to aggressive environments, especially due to chloride, sulphate and acid attacks. The calcium silicate hydrate $(\mathrm{CSH})$, while responsible for the majority of the strength and binding properties of cementitious products, is also vulnerable to chemical degradation. This means that a calcium-free binder would constitute a competitive substitute for more common cementitious materials, such as cement or lime. In terms of environmental performance, the absence of a specific high-temperature calcination step in the production of the AA precursors (i.e. fly ash) results in a dramatic reduction in $\mathrm{CO}_{2}$ emissions relatively to cement production. However, the advantages of AA over cement are not only environmental, since it has also proved to be more effective in terms of durability (Fernández-Jimenez et al., 2006b; Law et al., 2012; Reddy et al., 2013) and at least as effective in terms of mechanical behavior (Fernández-Jimenez et al., 2006c; Yazıc1 et al., 2008).

Even more recent is the study of alkaline activation of fly ash in soil stabilization. The available results comparing AA and cement-based binders have proved the technical and economic 
viability of the former (Cristelo et al., 2012a, 2013; Rao et al., 2014; Sukmak et al., 2015). However, an attempt to establish a framework enabling the consistent use of this technology in applications requiring artificially cemented soils has not yet been attempted. Such framework needs to be developed based on advanced soil mechanics models. Therefore, the research project described in the present paper aims to characterize, based on uniaxial and triaxial tests, the stress-strain behavior of a residual soil from granite, from the Porto region, stabilized with alkali-activated fly ash.

\section{Methodology}

\section{Materials}

The soil used in this study, very common in the northeast region of Portugal, was a silty sand resulting from residual granite. It was collected near the Faculty of Engineering of the University of Porto, and has been fully characterized in previous works, in its natural (Viana da Fonseca et al., 2006) and remolded condition (Amaral et al., 2012, Viana da Fonseca et al., 2013). Geotechnical characterization provided the grain size distribution curve of the soil and some additional information, presented in Figure 1 and Table 1, respectively. Using ASTM D2487-11 (2011), and based on the properties shown in Table 1, the soil was classified as a well-graded non-plastic silty sand - SM.

The fly ash (FA) (classified as Class F due to lower calcium content, according to ASTM C618, 2012) was produced by a Portuguese coal-fired thermo-electric power plant. Its particle size 
distribution curve (Figure 1) was determined by laser diffraction, using an analyzer from Beckman Coulter.

Microstructural characterization was attained using the Scanning Electron Microscopy (SEM) and X-Ray Diffraction (XRD). Energy Dispersive Spectroscopy (EDS) was additionally used to determine element composition of the soil-ash mixtures after 28 days of curing. The SEM equipment was a FEI QUANTA - 400 electronic microscope, with a tungsten filament electron source and $20 \mathrm{kV}$ accelerating voltage. The analyses were conducted in low vacuum mode, coupled with an X-ray energy dispersive spectrometry system (EDS) from EDAX. The mineralogy was examined by a PANalytical X'Pert Pro diffractometer, fitted with an $X^{\prime}$ Celerator detector. The scans covered the range 5 to $70^{\circ} 2 \theta$, with a nominal step size of $0.017^{\circ} 2 \theta$ and time of $100 \mathrm{sec}$ per step. CuK $\alpha$ radiation, with a wavelength of $\lambda=1.54180 \AA$, was used. Qualitative phase identification was made using High Score Plus software, which utilizes the International Centre for Diffraction Data Power Diffraction File database (ICDD PDF-2, Sets 1-49, 1999) as a reference.

SEM micrographs were used to analyze the morphology of ash particles (Figure 2) and the evolution of the interaction between soil and ash particles with curing (Figure 9). EDS semiquantitative chemical analyses (Table 2) revealed that approximately $90 \%$ of the soil elements are silica and alumina, while the fly ash has a low calcium content $(<5 \%)$ as expected. The $\mathrm{X}$ Ray diffraction pattern showed the presence of quartz, kaolinite and moskvinite as the main minerals on the soil mineralogy, and quartz, mullite and hematite on the fly ash mineralogy ( Figure 3). The halo between $17^{\circ} 2 \theta$ and $35^{\circ} 2 \theta$ clearly identified the vitreous phase of the ash, which is essential in alkali activation reactions. 
The activator was prepared using a sodium silicate (SS) to sodium hydroxide (SH) mass ratio of $1: 2$. The SS was originally in solution form, with a bulk density of $1.464 \mathrm{~g} / \mathrm{cm}^{3}$ at $20^{\circ} \mathrm{C}$, a $\mathrm{SiO}_{2} / \mathrm{Na}_{2} \mathrm{O}$ weight ratio of 2.0 (molar oxide ratio of 2.063 ) and $\mathrm{Na}_{2} \mathrm{O}$ concentration in the solution of $13.0 \%$. The SH was originally supplied in pellets with a specific gravity of 2.13 at $20^{\circ} \mathrm{C}(99 \mathrm{wt} \%)$, and was dissolved in water to form a 7.5 molal solution.

\section{Definition of mixtures}

Three types of alkaline activated mixtures were studied, with different FA percentages of $15 \%$, $20 \%$ and $25 \%$, relatively to the total solids weight (soil+ash). Additionally, specimens with the same soil/ash ratios and a liquid phase only constituted by water were also fabricated for comparison purposes. The identification of all the mixtures is shown in

Table 3, together with its main properties.

The definition of the composition of the mixtures involved a thorough process, based on several intrinsic aspects of both soil mechanics and alkaline activation reactions, which resulted in a few compromises. Regarding the fact that these mixtures are still, in essence, a granular material that behaves according to the fundamental theories of soil mechanics, it is obvious that density is a factor to consider when dealing with stiffness and strength. On the other hand, the liquid to solid ratio is also very important in terms of its influence on the alkaline activation reactions, since it indirectly controls some other fundamental values, such as the sodium to ash ratio $\left(\mathrm{Na}_{2} \mathrm{O} / \mathrm{ash}\right)$ or the total soluble silica $\left(\mathrm{SiO}_{2}\right)$ in the mixture. The effect of the fly ash content on soil behavior was one of the main objectives pursued in this research work, and so its value was different for each mixture, while the values of the unit weight, $\mathrm{NaOH}$ 
concentration and $\mathrm{Na}_{2} \mathrm{O} /$ ash ratio were maintained constant at $20 \mathrm{kN} / \mathrm{m}^{3}, 7.5$ molal and 0.125 , respectively. However, to achieve such combinations of values, it was not possible to use the same activator content and dry unit weight for each of the three mixtures. Therefore, the chosen dry unit weight values were in accordance with the results from the Standard Proctor test, performed on a mixture of $80 \%$ soil and $20 \%$ ash, whose liquid phase was the activator with $\mathrm{SS} / \mathrm{SH}$ ratio of 0.5 , so no more water was added to the mixture (Figure 4). Mixture M1 was prepared for the Proctor optimum dry unit weight of $18.2 \mathrm{kN} / \mathrm{m}^{3}$ with the activator content of $11.7 \%$ equal to the optimum water content of the Proctor curve. The other two mixtures were molded on the wet side of the Proctor's curve of the mixture with activator contents of $15.6 \%$ and $19.5 \%$ as expressed in

Table 3.

Specimen fabrication and testing

After the soil was collected and air dried, a thorough manual de-flocculation of the particles was promoted, followed by an additional oven drying period of $24 \mathrm{~h}$. The activator was produced approximately $6 \mathrm{~h}$ before its use, to allow for temperature stabilization at approximately $20^{\circ} \mathrm{C}$. The solids were initially mixed for $10 \mathrm{~min}$, followed by another $10 \mathrm{~min}$ of solids + activator mixing. The resulting paste was then divided into three equal portions, which were subsequently compacted in three layers inside a $70 \mathrm{~mm}$ diameter cylindrical metallic mold, forming $140 \mathrm{~mm}$ high specimens with the corresponding predetermined unit weight. After compaction, the top and bottom of the mold were covered with cling film, which was then stored in a room with controlled temperature $\left(20^{\circ} \mathrm{C}\right)$ and humidity $(85 \% \mathrm{RH})$. After 48 hours, the specimens were removed from the mold and wrapped in cling film, before being 
stored again in the controlled temperature and humidity room. After the curing period, and immediately before being tested, each specimen was carefully measured and weighted. Curing periods of 28 and 90 days were considered.

A $100 \mathrm{kN}$ automatic hydraulic testing machine was used for the uniaxial compression strength (UCS) tests, fitted with a $50 \mathrm{kN}$ capacity and $0.006 \mathrm{kN}$ resolution load cell. For reproducibility reasons, each UCS result is the average of three tested specimens. The tests were carried out under monotonic displacement control, at a rate of $0.1 \mathrm{~mm} / \mathrm{min}$ (slower than the value recommended by ASTM D1633 (2007)), in order to perform small unload-reload cycles in some of the specimens. Local deformation transducers (LDTs) were used for increased strain measurement accuracy (Goto et al., 1991; Hayano et al., 1997).

While UCS tests are widely used as an index for quantifying the extent of soil improvement, it is well-known that soil behavior is highly dependent on confining pressure. Therefore, a series of consolidated-drained (CD) triaxial compression tests with volumetric strain measurement were conducted on specimens from the three mixtures considered in this study, in order to thoroughly examine the stress-strain behavior. This information is considered essential to evaluate the suitability of the treated material for almost all types of applications, such as embankments, jet grouting columns, road pavement foundations and structural foundations. A 28-day curing period was chosen, and three different tests, using three different consolidation pressures, were carried out for mixtures M1 and M3. These mixtures were chosen because they showed the highest and lowest uniaxial compression strength, respectively. Later on, two additional tests were performed for mixture M2, with the highest and lowest confining stresses considered for the other mixtures. All the tests were performed using Hall-Effect Transducers 
(Clayton et al., 1989) glued to the membrane around the specimen, for local strain measurement.

After the 28 days of curing period, the specimens were submerged in water for $24 \mathrm{~h}$, prior to being mounted on the triaxial cell. After installation in the testing chamber, the percolation phase followed, by forcing the water to flow between the bottom and top of the specimen. Such procedure allowed the removal of most of the air trapped in the system. Since the permeability of this material is very low $\left(\mathrm{k} \approx 10^{-9} \mathrm{~m} / \mathrm{s}\right.$, measured during the percolation stage), filter paper stripes were placed around the specimen to facilitate percolation. When the total volume of percolated water reached the double value of the voids ratio, the saturation stage was initiated at a constant isotropic effective stress of $10 \mathrm{kPa}$, with back and cell pressure continuously increasing at a $30 \mathrm{kPa} / \mathrm{h}$ rate until reaching 500 and $510 \mathrm{kPa}$, respectively. The specimen was then left to stabilize for at least 5 hours. Isotropic consolidation followed, at the same increasing stress rate of $30 \mathrm{kPa} / \mathrm{h}$, but in this case only the cell pressure was increased, until reaching isotropic effective confining pressures of 25,75 and $150 \mathrm{kPa}$. The specimens were then anisotropic consolidated, following a coefficient of earth pressure at rest $K_{0}$ of 0.5 , for which the axial stresses (corresponding to deviator stresses) were increased to 25,75 and $150 \mathrm{kPa}$, respectively, using the loading frame system. These consolidation stresses were defined based on the average effective stresses expected at 5, 15 and $30 \mathrm{~m}$ deep points in a normally consolidated, saturated soil mass with a $20 \mathrm{kN} / \mathrm{m}^{3}$ unit weight, admitting a coefficient of earth pressure at rest $\left(\mathrm{K}_{0}\right)$ of 0.5 . After stabilization of the volume change, the shearing stage would begin, again under monotonic displacement control, but in this case at a rate of $0.01 \mathrm{~mm} / \mathrm{min}$. Such relatively low displacement rate was defined so that drained tests would not generate significant excess pore pressures. 


\section{Results}

\section{Strength analysis}

Uniaxial compression strength tests were performed on specimens from all the mixtures presented in Table 3 after 28 and 90 days of curing. The results of the maximum stress values obtained for each mixture, as presented in Figure 5, are the average of three UCS tests. The use of local strain instrumentation by means of LDTs allowed a more accurate definition of the stress-strain curves, from which a representative example of each case is presented in Figure 6 , clearly showing the significant effect of the alkaline binder on the strength increase. Such improvement has already been reported by Cristelo et al. (2011, 2012b), although using different activator compositions. The initial tangent stiffness obtained from the initial part of the stress-strain curves also showed a significant increase due to the alkaline binder, indicating that both strength and stiffness are affected by this stabilization. In agreement with the strength values, M1 mixture showed higher stiffness value, followed by M2, being M3 the most flexible.

Another important observation concerns the strength evolution between 28 and 90 days of curing. The 28-day mark is a reference for strength characterization of cement-based materials. Such binders heavily depend on a specific alkaline-earth element, i.e. calcium, and the main reaction product is a C-S-H gel. On the contrary, the fly ash used in this study has a low calcium content and therefore its geopolymerization yields mostly $\mathrm{Si}-\mathrm{O}-\mathrm{Al}$ and $\mathrm{Si}-\mathrm{O}-\mathrm{Si}$ gels (Fernández-Jiménez and Palomo, 2003). The complex chemistry regarding geopolymer development is beyond the scope of the present paper, but it is important to understand that the 
rate of formation of both gel types previously mentioned is rather different, with the low-Ca reaction product requiring longer curing periods to form and crystallize than the high calcium content. Basically, this is a consequence of the different nature of the soluble or glassy mass governing each material, in the sense that a calcium-based glass structure is more reactive with water than a siliceous-based glass structure (Diaz et al., 2010). The results presented show that the UCS of the low-Ca geopolymer almost doubled between the 28 and 90 days of curing, in agreement with previous research (Cristelo et al., 2011, 2013). However, even if strength is continuously increasing, for tight construction projects it is not necessary to wait for such a long time, since considerable strength is obtained for smaller periods. This particular study did not focus on the short term strength and so there are no results at 7 days of curing, but depending on the application the mixture can be adjusted so that enough strength is obtained at 7 days or other shorter period considered relevant.

Figure 5 shows that the increase of the liquid or ash content resulted in a strength reduction, while an increase in dry unit weight was responsible for an increase in strength. This means that the compaction point given by the liquid content and dry unit weight has a higher influence than the amount of fly ash. Note that a constant unit weight was used to fabricate the three mixtures $\left(20 \mathrm{kN} / \mathrm{m}^{3}\right)$, i.e. only the dry unit weight was changed. Considering these results, the mixture M1 showed the best performance. At 28 days the mixture M2 presents higher strength than M3, however, at 90 days the mixture M3 presented higher strength. It is important to highlight that the lower performing mixtures showed the higher increase in strength due to the effect of the activator. The increase in strength between the non-stabilized and the 90 days stabilized soils is $16 \mathrm{x}, 31 \mathrm{x}$ and 77x higher, for mixtures M1, M2 and M3, respectively, as summarized in Table 4. This larger increase obtained for the less compacted mixture M3 was expected, since its initial density - and therefore its strength - was significantly lower than that 
of the M1, and indicates that even low compacted mixtures can be highly improved by the cementation provided by this technique.

Triaxial test results evidenced very stiff stress-strain curves, as illustrated in Figure 7, with an initial volume reduction followed by significant dilation. Mixture M1 showed higher peak deviator stresses, higher initial stiffness (lower strain at peak stress) and higher dilation than the other mixtures. In any case, all specimens revealed strain localisation during shearing, which can be verified by the sudden strain softening observed in the volumetric strain versus axial strain plot (Figure 7), as well as by the failure mode shown in Figure 8.

Figure 9 shows the strength envelope in the $q$ vs $p^{\prime}$ space obtained from the results of the triaxial tests presented above for M1 and M3 mixtures. Values of the angle of shearing resistance higher than $60^{\circ}$ were obtained, especially for M1, associated to cohesion intercepts around $200 \mathrm{kPa}$, and very high dilatancy angles without physical significance which were not presented. These high peak values for the angle of shearing resistance and also for dilation angles is typical of granular materials in cemented conditions, as discussed in Viana da Fonseca et al. (2014).

Scanning electron microscopy (SEM/EDS)

As observed in Figure 2 the ash particles are solid spheres because, as explained by Kutchko and Kim (2006), the morphology of a fly ash particle is controlled by the combustion temperature and cooling rate. Rapid cooling in the post-combustion zone results in the formation of spherical, amorphous (non-crystalline) particles. 
The evolution of the microstructural morphology throughout the curing process is very similar for the three mixtures. For that reason, the results are presented only for a sample of M2 mixture, which is shown in the micrographs of Figure 10 where a particular soil particle surrounded by ash-activator paste is highlighted. This paste clearly evolved with curing time, forming the aluminosilicate gel, typical of these low-Ca alkali activated blends. In Figure 11, one detail of this sample was chosen in order to illustrate some examples of the modifications developed from the instant of mixture preparation (A) up to 90 days of curing (B). It is possible to see the mitigation of the spherical shape of some of the ash particles, after being dissolved in the high alkaline environment created by the hydroxide, and the corresponding dissemination of the aluminosilicate gel, binding the soil with the remaining ash particles. The evolution of this gel is thought to be responsible for the mechanical improvements analyzed in the previous sections, and this is expected to continue beyond the 90-days curing period, until a complete zeolite structure is formed.

The M2 aluminosilicate gel was characterized with EDS to obtain a qualitative analysis of the main reaction products (point 1 shown in Figure 11). After 90 days of curing, the aluminosilicate gel incorporated elements from both the fly ash and the activator, namely silica, alumina and sodium (Table 5). Furthermore, relatively to the element composition of the original fly ash (Table 2), it is worth noting an increase in silica and sodium, and a decrease in the content of all the other remaining main elements, especially iron. This increase in the silica's relative weight is in accordance with previous research (Favier et al., 2013).

\section{Discussion}


Data from the alkali-activated mixtures was compared with previous results obtained from tests on soil-cement specimens molded according to the methodology previously described for the soil-ash specimens. The same soil was used and similar void ratios were also adopted. Figure 12 shows a comparison between the soil-ash UCS results previously presented in this paper, together with the soil-cement UCS data presented by Rios (2011), using 5\% and 7\% cement contents. These specific cement contents were chosen to be presented in this paper because their respective UCS values at 28 days are similar to those obtained for the alkali activated mixtures. Although the soil-cement results were obtained only up to 56 days of curing, the strength evolution was extrapolated up to 90 days using Equation 5 from ACI Committee 209 (1998). The referred model was developed for concrete applications, but it does fit reasonably well the experimental results, if $a$ and $b$ parameters are conveniently calibrated for this cemented material:

$$
f_{c}(t)=f_{c}(28) \cdot \frac{t}{a+b \cdot t}
$$

where $f_{c}(t)=$ compressive strength at instant $t ; f_{c}(28)=$ reference 28 -day compressive strength; $a, b=$ calibrated coefficients $(\mathrm{a}=3.92$ and $\mathrm{b}=0.86)$.

It can be observed that the UCS of the alkali activated mixtures is significantly higher than that obtained for the soil-cement, at least for longer curing periods. At shorter curing periods, the UCS of the cement-stabilized soil increases more rapidly, due to the faster dissolution rate of the calcium-type glassy material, forming the $\mathrm{C}-\mathrm{H}-\mathrm{S}$ gel that can be found in cement hydration.

It is very difficult to achieve a reliable no-volume change plateau in these very stiff materials, since the peak stress is followed by strain localization in a shear plane, and so the stress invariants are no longer valid (Burland, 1990). In these cases, stress-dilatancy data may give an additional help in the interpretation of triaxial test results, as shown by Alvarado and Coop 
(2011) and Coop and Willson (2003), among others. Figure 13 shows the typical stressdilatancy behavior of cemented soils. Initially, there is very small volumetric deformation resulting in low dilatancy angles, until a maximum stress is reached and significant dilation occurs from then on. After a peak, a reduction of the dilatancy occurs together with the stress ratio, but strain localization of the specimens resulted on a more rapid decrease of the dilation rate than of the stress ratio, thus leading the stress-path towards the inside of the frictional trend of the silty sand in non-cemented conditions (Rios et al., 2013). However, as observed by Alvarado et al. (2012), the stress-dilatancy behavior tends to become closer to the frictional trend as the confining stress increases. For mixture M2, at the highest confining stress $\left(\sigma^{\prime}{ }_{1}=300\right.$ $\mathrm{kPa}$ and $\sigma^{\prime}{ }_{3}=150 \mathrm{kPa}$ ), the stress ratio tended to an $\mathrm{M}$ value of approximately 1.6 (being $\mathrm{M}$ the slope at the critical state) indicating that, in this case, the confining pressure may be destroying particle bonding. In the other tests, the stress ratio tended to a higher $\mathrm{M}$ value of approximately 2, in agreement with the soil-cement data presented by Rios et al. (2013).

\section{Conclusions}

This paper presents the geomechanical characterization of a new type of artificially cemented soil resulting from the alkaline activation of fly ash, which creates a geopolymeric gel that links the soil particles. A significant advantage of this new material in comparison with traditional soil-cement is its environmentally friendly nature, since no $\mathrm{CO}_{2}$ is generated to obtain the precursor used in this process. The performance of this new material was analyzed by means of unconfined compression tests, triaxial tests and scanning electron microscopy and the results were compared with previously obtained soil-cement data. 
The mixture that showed the higher strength was M1, with higher dry unit weight, indicating that compaction is more important than the amount of fly ash or activator type. Comparing to the soil-ash mixtures without alkaline activator, the alkaline activated specimens show a significant increase in strength. For instance, M1 strength evolved from 0.3 to $2.8 \mathrm{MPa}$ at 28 days and to 5.2 MPa at 90 days. This was even more evident in the lower performing mixtures indicating that low compacted mixtures can also be highly improved by this stabilization technique.

Triaxial tests on alkaline activated specimens showed very stiff stress-strain curves with an initial volume reduction followed by significant dilation. All specimens suffered strain localization during shearing, and so ultimate behavior was analyzed from stress-dilatancy results where an $\mathrm{M}$ value of 2 was obtained for mixture M1 and M3, corresponding to a $\phi^{\prime}{ }_{\mathrm{CV}}$ of $48^{\circ}$. The peak strength envelope gave very high angles of shearing resistance $\left(49^{\circ}\right.$ for M3 and $65^{\circ}$ for M1) together with cohesion intercepts of $250 \mathrm{kPa}$ for M3 and $290 \mathrm{kPa}$ for M1.

Soil-cement and alkaline activated specimens show a similar type of cementation, characterized by a significant increase in strength. The main difference between the two binders is the curing rate, with cement showing a significant strength development at an earlier age and stabilizing after curing for 28 days, while alkali-activated mixtures showed a slower, more progressive and long-lasting strength increase, with significant improvements between the $28^{\text {th }}$ and $90^{\text {th }}$ day mark. Despite this difference, shearing appears to destroy similarly both cementation bonds since identical $\mathrm{M}$ values were obtained in soil-cement and alkali activated soil-ash mixtures.

SEM micrographs taken up to 90 days of curing clearly showed the dissolution of most ash particles and the corresponding formation of the aluminosilicate gel. The apparently slow 
development rate of the gel is thought to be responsible for the lower strength evolution of the alkali activated mixtures, when compared with the soil-cement mixtures.

\section{Acknowledgements}

The authors would like to acknowledge the Chemical Engineering Department of University of Porto, namely Professors Fernão Magalhães and Adélio Mendes, for the use of the Particle Size Analyser; the company Pegop - Energia Eléctrica SA which runs the thermoelectric power plant of Pego, for the supply of fly ash; the Electronic Microscopy Unit at the University of Trás-os-Montes e Alto Douro, for the SEM, EDS and XRD analysis; the MCTES/FCT (Portuguese Science and Technology Foundation of Portuguese Ministry of Science and Technology) for their financial support through the SFRH/BPD/85863/2012 scholarship; to ANI (Agência Nacional de Inovação) for their support through ECOSOLO project (FCOMP01-0202-FEDER-038899) and to Marco de Laureto for the help in the laboratory work.

\section{References}

ACI Committee 209 (1998). Prediction of Creep, Shrinkage, and Temperature Effects in Concrete Structures. Committee Report ACI 209R-92. ACI Man. Concr. Pract. Part I.

Alvarado, G., Coop, M. (2011). On the performance of bender elements in triaxial tests. Géotechnique 62, 1-17.

Alvarado, G., Coop, M., Willson, S. (2012). On the role of bond breakage due to unloading in the behaviour of weak sandstones. Géotechnique 62, 303-316.

Amaral, M., Rios, S. and Viana da Fonseca, A. (2012). Yielding in isotropic compression of Porto silty sand. Acta Geotechnica Slovenica 9, 31-45

ASTM D2487-11 (2011). Standard Practice for Classification of Soils for Engineering Purposes (Unified Soil Classification System). Am. Soc. Test. Mater. 
ASTM C618 (2012). Standard specification for coal fly ash and raw or calcined natural pozzolan for use in concrete. ASTM Int. Annu. B. Stand. 1-5.

ASTM D1633 (2007). Standard Test Methods for Compressive Strength of Molded Soil-Cement Cylinders. Am. Soc. Test. Mater.

Burland, J.B. (1990). On the compressibility and shear strength of natural clays. Géotechnique 40, 329-378.

Clayton, C., Khatrush, S., Bica, A., Siddique, A. (1989). The Use of Hall Effect Semiconductors in Geotechnical Instrumentation. Geotech. Test. J. 12, 69-76.

Coop, M.R., Willson, S.M. (2003). Behavior of Hydrocarbon Reservoir Sands and Sandstones. J. Geotech. Geoenvironmental Eng. 129, 1010-1019.

Cristelo, N., Glendinning, S., Pinto, A.T. (2011). Deep soft soil improvement by alkaline activation. Proc. ICE Gr. Improv. 164, 73-82.

Cristelo, N., Glendinning, S., Fernandes, L., Pinto, A.T. (2012a). Effect of calcium content on soil stabilisation with alkaline activation. Constr. Build. Mater. 29, 167-174.

Cristelo, N., Glendinning, S., Miranda, T., Oliveira, D., Silva, R.. (2012b). Soil stabilisation using alkaline activation of fly ash for self compacting rammed earth construction. Constr. Build. Mater. 36, 727-735.

Cristelo, N., Glendinning, S., Fernandes, L., \& Teixeira Pinto, A. (2013). Effects of alkaline-activated fly ash and Portland cement on soft soil stabilisation. Acta Geotechnica, 8, 395-405. doi: 10.1007/s11440-0120200-9

Davidovits, J. (1991). Geopolymers - Inorganic polymeric new materials. Journal of Thermal Analysis 37: $1633-1656$.

Diaz, E.I., Allouche, E.N., Eklund, S. (2010). Factors affecting the suitability of fly ash as source material for geopolymers. Fuel 89, 992-996.

Duxson, P., A. Fernandes-Jiménez, J. L. Provis, G. C. Luckey, A. Palomo and J. S. J. van Deventer (2007). Geopolymer technology: the current state of the art. Journal of Materials Science 42: 2917-2933.

Favier, A., Habert, G., d'Espinose de Lacaillerie, J.B., Roussel, N. (2013). Mechanical properties and compositional heterogeneities of fresh geopolymer pastes. Cem. Concr. Res. 48, 9-16.

Fernández-Jiménez, A. and A. Palomo (2003). Characterisation of fly ashes. Potential reactivity as alkaline cements. Fuel 82(18): 2259-2265.

Fernández-Jiménez, A., A. Palomo and M. Criado (2005a). Microstructure development of alkali-activated fly ash cement: a descriptive model. Cement and Concrete Research 35: 1204-1209. 
Fernández-Jiménez, A., Palomo, A. (2005b). Composition and microstructure of alkali activated fly ash binder:Effect of the activator. Cem. Concr. Res. 35, 1984-1992.

Fernández-Jiménez, A., A. Palomo, I. Sobrados and J. Sanz (2006a). The role played by the reactive alumina content in the alkaline activation of fly ashes. Microporous and Mesoporous Materials 91: 111-119.

Fernández-Jimenez, A., García-Lodeiro, I., Palomo, A. (2006b). Durability of alkali-activated fly ash cementitious materials. J. Mater. Sci. 42, 3055-3065.

Fernández-Jimenez, A., Palomo, A., Lopez-Hombrados, C. (2006c). Engineering properties of alkali-activated fly ash concrete. Mater. J. 103, 106-112.

Goto, S., Tatsuoka, F., Shibuya, S., Kim, Y., Sato, T. (1991). A Simple Gauge for Local Small Strain Measurements in the Laboratory. Soils Found. 31, 169-180.

Hayano, K., Tatsuoka, F., Sato, T. (1997). Deformation characteristics of a sedimentary soft mudstone from triaxial compression tests using rectangular prism specimens. Géotechnique 47, 439-449.

He, J., J. Zhang, Y. Yu and G. Zhang (2012). The strength and microstructure of two geopolymers derived from metakaolin and red mud-fly ash admixture: A comparative study. Construction and building materials 30: 80-91.

Kutchko, B. G. and A. G. Kim (2006). Fly ash characterization by SEM-EDS. Fuel 85(2537-2544).

Law, D.W., Adam, A.A., Molyneaux, T.K., Patnaikuni, I. (2012). Durability assessment of alkali activated slag (AAS) concrete. Mater. Struct. 45, 1425-1437.

Provis, J., Deventer, J. van (Eds.). (2014). Alkali Activated Materials: State-of-the-art Report, RILEM TC 224AAM. Springer.

Rao, S. and P. Acharya (2014). Synthesis and Characterization of Fly Ash Geopolymer Sand. Journal of Materials in Civil Engineering 26(5): 912-917.

Reddy, D. V., Jean-Baptiste, E. and Sobhan, K. (2013). Durability of Fly Ash-Based Geopolymer Structural Concrete in the Marine Environment. Journal of Materials in Civil Engineering 25(6): 781-787.

Rios, S. (2011). A General Framework for the Geomechanical Characterisation of Artificially Cemented Soil PhD Thesis. Faculty of Engineering of University of Porto.

Rios, S., Viana da Fonseca, A., Baudet, B.A. (2013). On the shearing behaviour of an artificially cemented soil. Acta Geotech. 9, 215-226. 
Viana da Fonseca, A., Carvalho, J., Ferreira, C., Santos, J. a., Almeida, F., Pereira, E., Feliciano, J., Grade, J., Oliveira, A. (2006). Characterization of a profile of residual soil from granite combining geological, geophysical and mechanical testing techniques. Geotech. Geol. Eng. 24, 1307-1348.

Viana da Fonseca, A., Rios, S., Amaral, M. F. (2013). Structural anisotropy by static compaction, Engineering Geology, 154, 89-97, http://dx.doi.org/10.1016/j.enggeo.2012.11.012

Viana da Fonseca, A., Amaral, M.F., Panico, F. and Rios, S. (2014). Indexation of Dynamic and Static Geomechanical Properties of a Cemented Aggregate for Transportation Engineering. Transportation Geotechnics, no. 1, 31-44, doi:10.1016/j.trgeo.2014.02.001

Sperinck, S., Raiteri, P., Marks, N. and Wright, K. (2011). Dehydroxylation of kaolinite to metakaolin-a molecular dynamics study. Journal of Materials Chemistry, 21, 2118-2125

Sukmak, P., Silva, P.D., Horpibulsuk, S. and Chindaprasirt, P. (2015). Sulfate Resistance of Clay-Portland Cement and Clay High-Calcium Fly Ash Geopolymer. Journal of Materials in Civil Engineering 27(5): 04014158.

Yazıcı, H., Yiğiter, H., Karabulut, A.Ş., Baradan, B. (2008). Utilization of fly ash and ground granulated blast furnace slag as an alternative silica source in reactive powder concrete. Fuel 87, 2401-2407. 


\section{List of tables}

Table 1: Geotechnical properties of the soil

\begin{tabular}{ll}
\hline Property & Value \\
\hline Plastic Limit & $\mathrm{NP}$ \\
Liquid Limit & $\mathrm{NP}$ \\
$\mathrm{D}_{50}$ & $0.25 \mathrm{~mm}$ \\
Specific gravity & 2.72 \\
${\text { Fines fraction (sieve } \mathrm{N}^{\mathrm{o}} \text { 200) }}^{\text {Uniformity Coefficient }}$ & $33 \%$ \\
Curvature Coefficient $_{\text {Optimum water content }}{ }^{\mathrm{a}}$ & 113.0 \\
Optimum water content $^{\mathrm{b}}$ & 2.7 \\
Maximum dry unit weight $^{\mathrm{a}}$ & $17.5 \%$ \\
Maximum dry unit weight $^{\mathrm{b}}$ & $13.0 \%$ \\
\hline
\end{tabular}

${ }^{\mathrm{a}}$ Standard Proctor test; ${ }^{\mathrm{b}}$ Modified Proctor test

Table 2: Composition of the soil and the fly ash (wt\%)

\begin{tabular}{lllllllllll}
\hline Element & $\mathrm{Si}$ & $\mathrm{Al}$ & $\mathrm{Fe}$ & $\mathrm{Ca}$ & $\mathrm{K}$ & $\mathrm{Ti}$ & $\mathrm{Mg}$ & $\mathrm{Na}$ & $\mathrm{S}$ & $\mathrm{P}$ \\
\hline Soil & 55.11 & 29.05 & 4.49 & - & 9.80 & 0.64 & 0.90 & - & - & - \\
Fly ash & 48.81 & 21.77 & 14.74 & 3.85 & 4.42 & 1.79 & 1.56 & 1.31 & 1.17 & 0.58 \\
\hline
\end{tabular}

Table 3: Characterization of all the mixtures analyzed

\begin{tabular}{lllllllll}
\hline ID & $\begin{array}{l}\text { Ash / } \\
\text { solids } \\
(\text { wt. })\end{array}$ & $\begin{array}{l}\mathrm{Na}_{2} \mathrm{O} / \\
\text { ash } \\
(\text { wt. })\end{array}$ & $\begin{array}{l}\mathrm{NaOH} \\
\text { concent. } \\
(\text { molal })\end{array}$ & $\begin{array}{l}\text { Water } \\
\text { content } \\
(\%)\end{array}$ & $\begin{array}{l}\text { Activ. } \\
\text { content } \\
(\%)^{\mathrm{a}}\end{array}$ & $\begin{array}{l}\text { Activ. } \\
/ \text { ash } \\
(\text { wt. })\end{array}$ & $\begin{array}{l}\text { Dry unit } \\
\text { weight } \\
\left(\mathrm{kN} / \mathrm{m}^{3}\right)\end{array}$ & $\begin{array}{l}\mathrm{SiO}_{2} / \\
\mathrm{Na}_{2} \mathrm{O} \\
(\mathrm{wt})^{\mathrm{c}}\end{array}$ \\
\hline M01 & 0.15 & - & - & 11.7 & - & - & 18.22 & - \\
M02 & 0.20 & - & - & 15.6 & - & - & 17.08 & - \\
M03 & 0.25 & - & - & 19.5 & - & - & 16.04 & - \\
\hline M1 & 0.15 & 0.125 & 7.5 & 8.8 & 11.7 & 0.781 & 18.22 & 0.552 \\
M2 & 0.20 & 0.125 & 7.5 & 11.7 & 15.6 & 0.781 & 17.08 & 0.552 \\
M3 & 0.25 & 0.125 & 7.5 & 14.7 & 19.5 & 0.781 & 16.04 & 0.552 \\
\hline
\end{tabular}

${ }^{\mathrm{a}}$ For a SS/SH ratio of 0.5 ; ${ }^{\mathrm{b}}$ For a unit weight of $20 \mathrm{kN} / \mathrm{m}^{3}$; ${ }^{\mathrm{c}}$ Quantities from the activator

Table 4: UCS results for the studied mixtures

\begin{tabular}{c|ccc|ccc|ccc}
\hline \multirow{2}{*}{ Specimens } & \multicolumn{3}{|c|}{ Non AA specimens } & \multicolumn{3}{c|}{ AA specimens (28 days) } & \multicolumn{3}{c}{ AA specimens (90 days) } \\
\cline { 2 - 22 } & M01 & M02 & M03 & M1 & M2 & M3 & M1 & M2 & M3 \\
\hline UCS $(\mathrm{kPa})$ & 298.6 & 111.3 & 48.1 & 2339.9 & 2144 & 1129.8 & 4836.4 & 3435.3 & 3692.7 \\
\hline M/M0 & - & - & - & 7.8 & 19.3 & 23.5 & 16.2 & 30.9 & 76.8 \\
\hline
\end{tabular}

${ }^{a}$ AA means alkaline activated

Table 5: Composition of the M2 aluminosilicate gel after 90 days of curing (wt\%)

\begin{tabular}{lllllllllll}
\hline Element & $\mathrm{Si}$ & $\mathrm{Al}$ & $\mathrm{Fe}$ & $\mathrm{Ca}$ & $\mathrm{K}$ & $\mathrm{Ti}$ & $\mathrm{Mg}$ & $\mathrm{Na}$ & $\mathrm{S}$ & $\mathrm{P}$ \\
\hline $\mathrm{Gel}^{\mathrm{a}}$ & 57.77 & 19.70 & 4.67 & 1.20 & 4.67 & 0.63 & 0.82 & 10.54 & 0.00 & 0.00 \\
\hline
\end{tabular}

${ }^{a}$ Point 1 in Figure 11 


\section{List of figures}

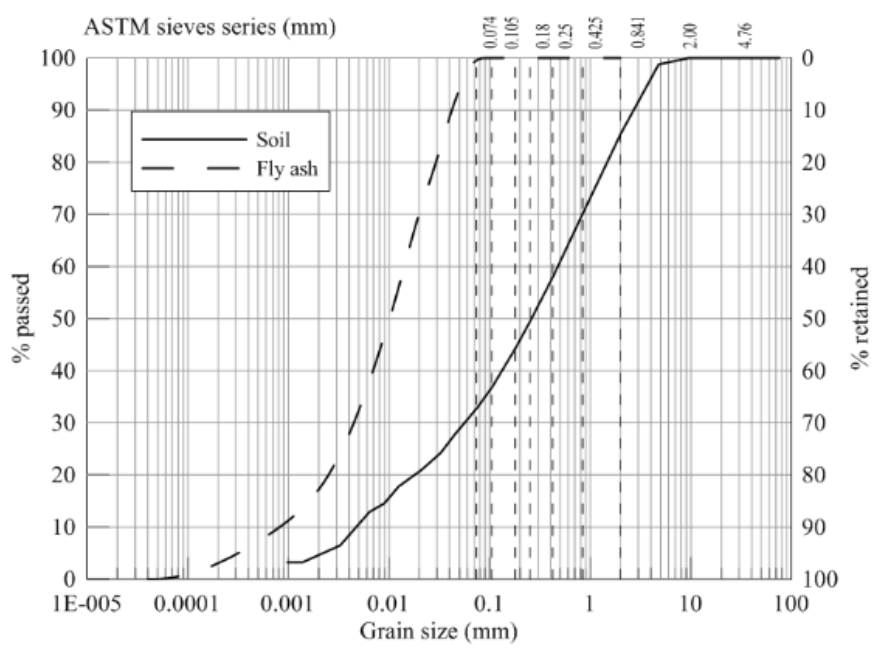

Figure 1: Grain size distribution of the soil and fly ash

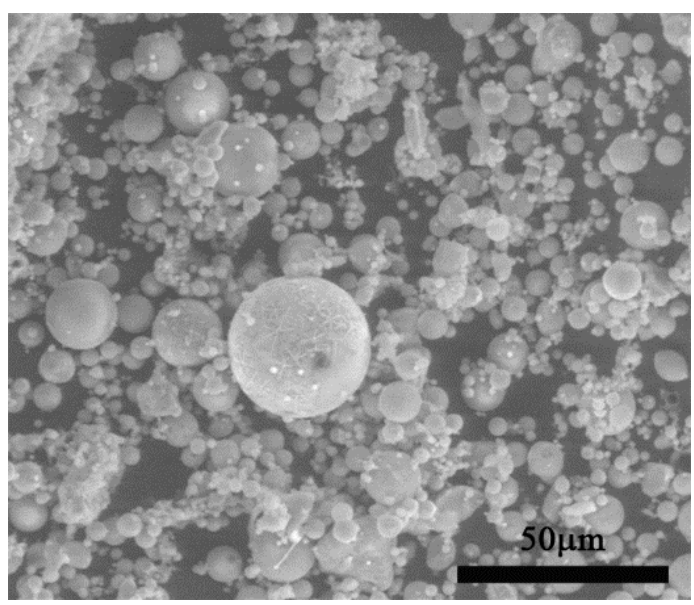

Figure 2: SEM micrograph of the original fly ash 


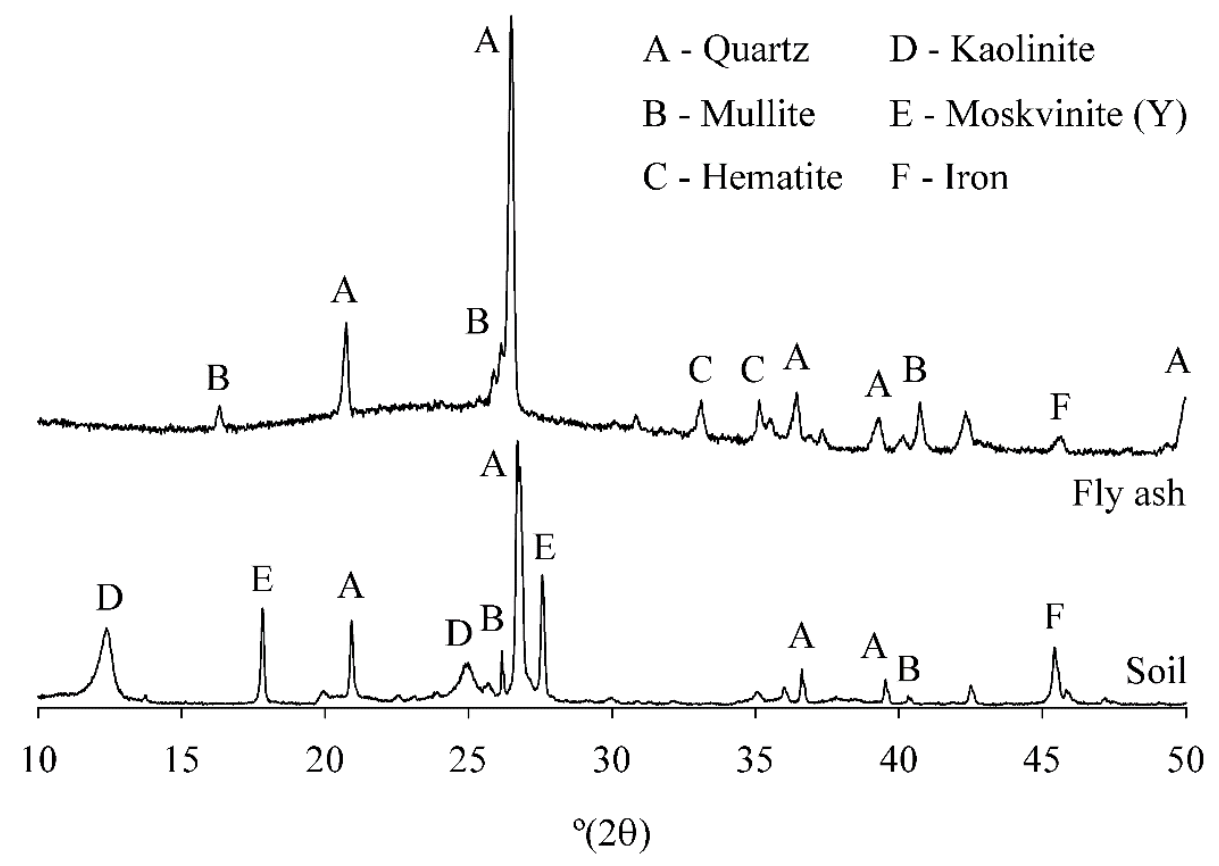

Figure 3: $\mathrm{Cu} \mathrm{K} \alpha$ diffractogram of the soil and the fly ash

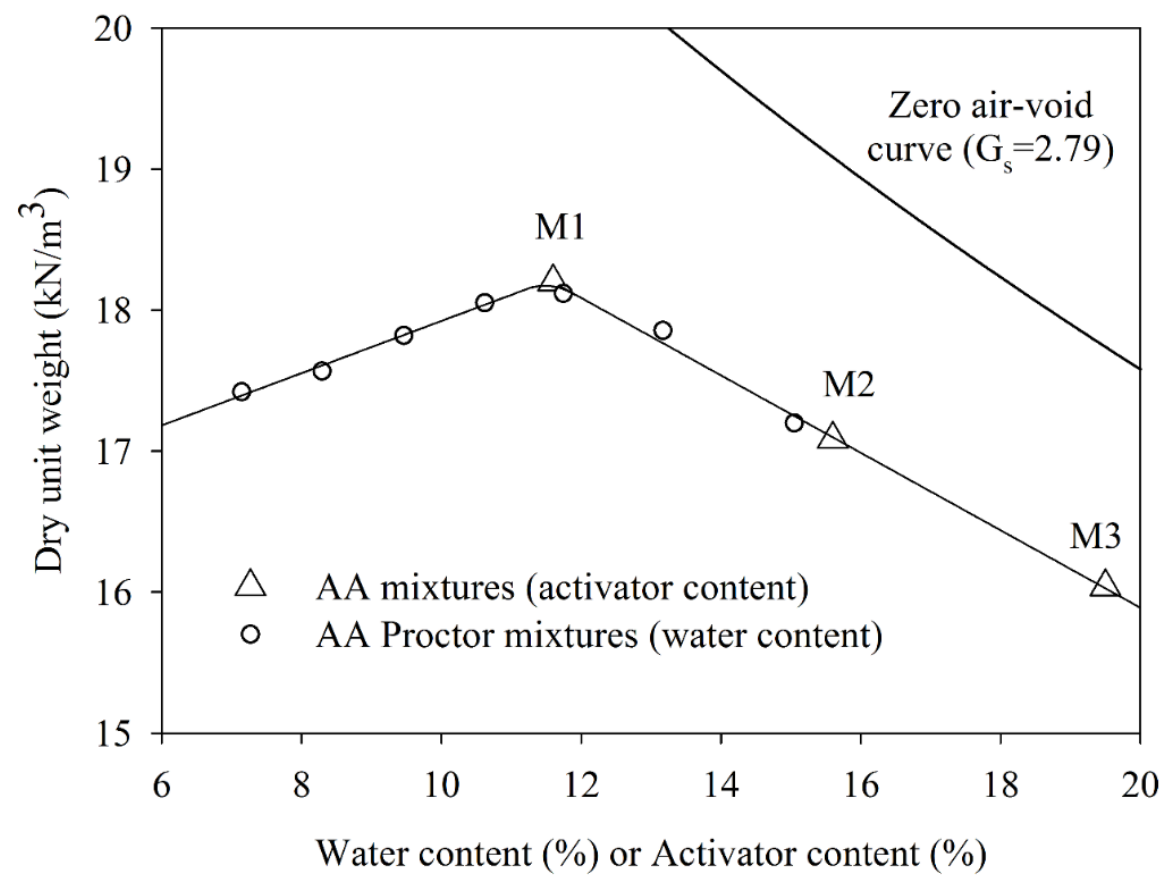

Figure 4: Proctor's curve and molding points of the three mixtures (M1, M2, and M3) 

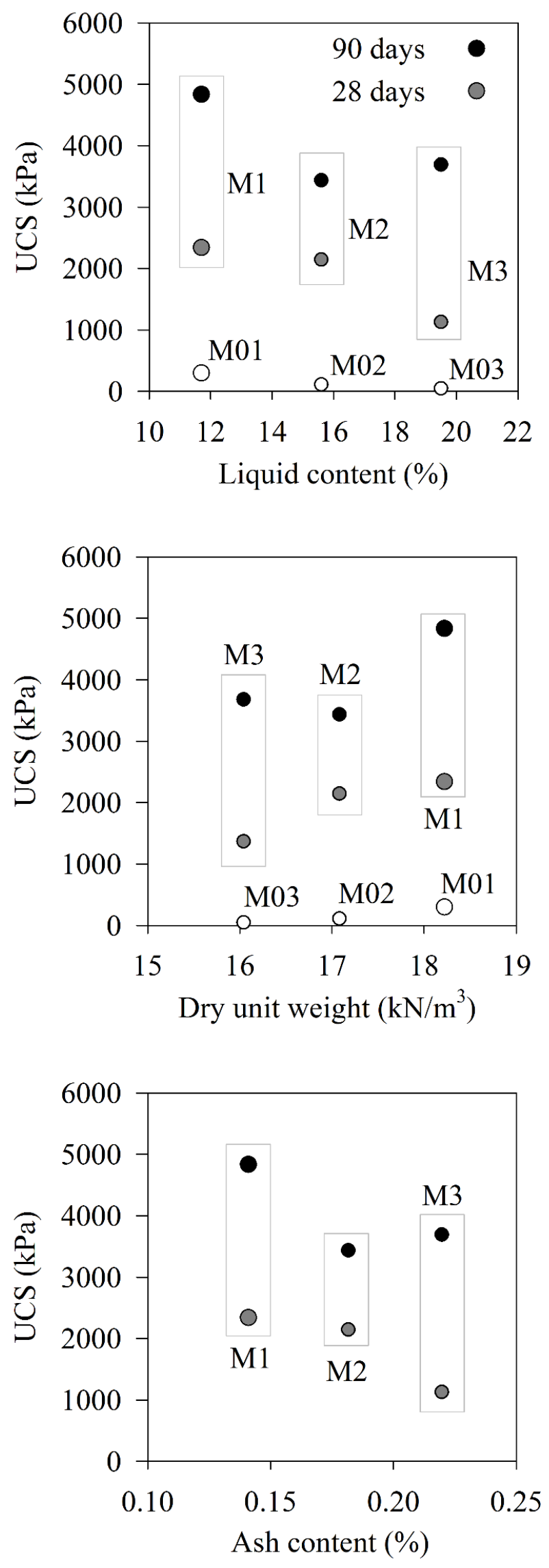

Figure 5: Overall unconfined compressive strength results 


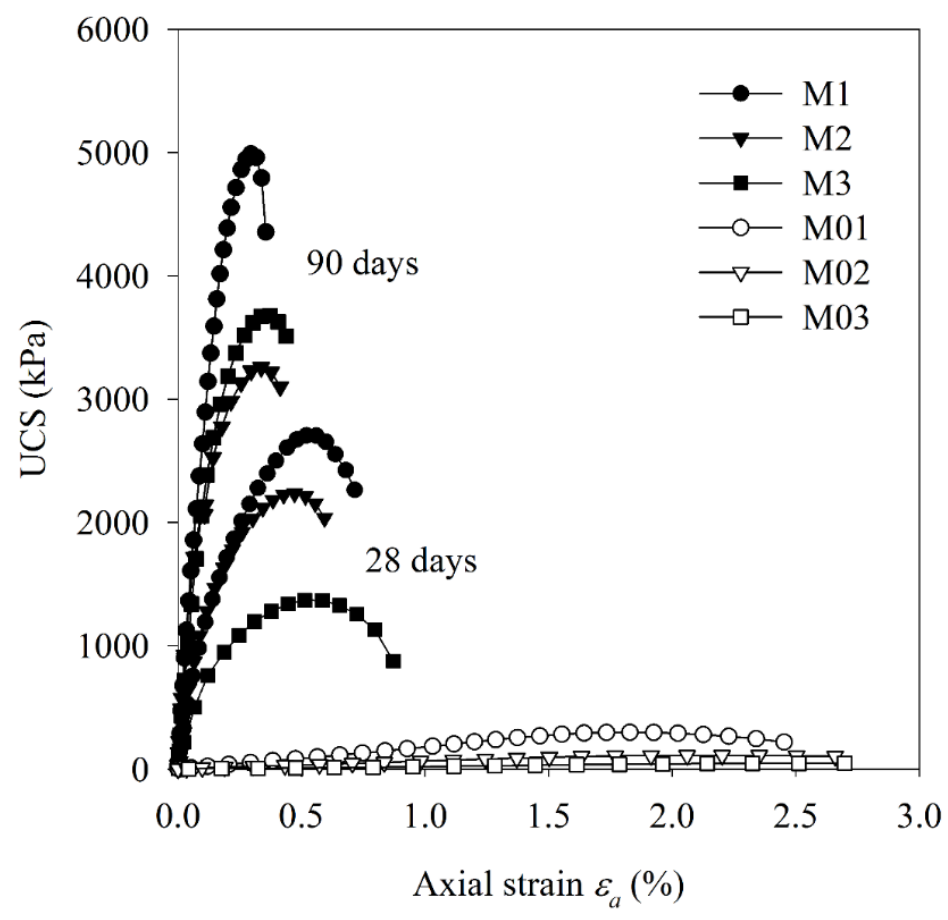

Figure 6: Stress-strain curves of selected UCS tests

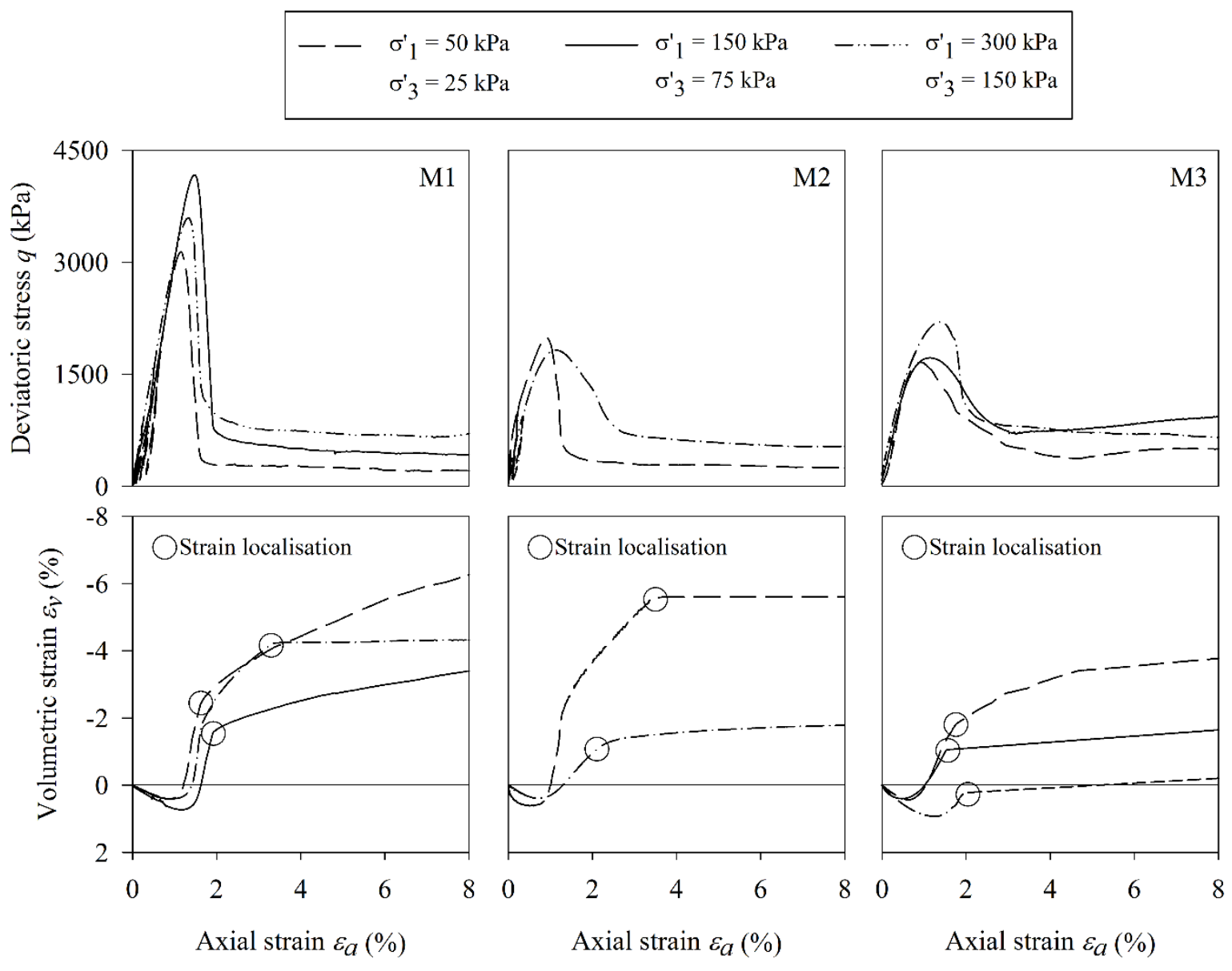

Figure 7: Triaxial compression tests, at 28 days of curing, at the following initial stresses: $\sigma^{\prime}{ }_{\mathrm{v} 0}=50 \mathrm{kPa}$ and $\sigma^{\prime}{ }_{\mathrm{h} 0}$ $=25 \mathrm{kPa} ; \sigma^{\prime}{ }_{\mathrm{v} 0}=150 \mathrm{kPa}$ and $\sigma^{\prime}{ }_{\mathrm{h} 0}=75 \mathrm{kPa}$; and $\sigma^{\prime}{ }_{\mathrm{v} 0}=300 \mathrm{kPa}$ and $\sigma^{\prime}{ }_{\mathrm{h} 0}=150 \mathrm{kPa}$ 


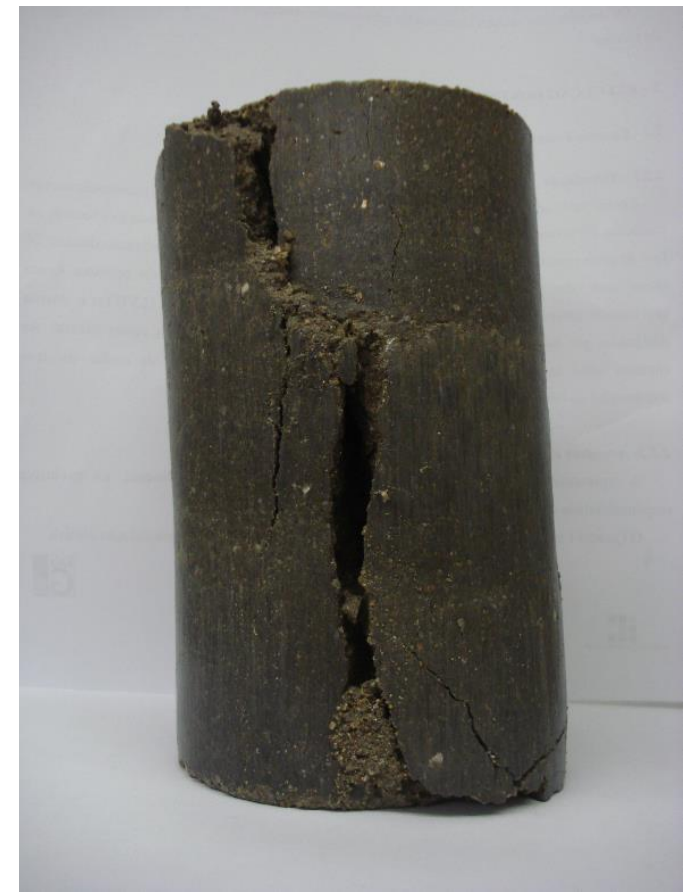

Figure 8: Triaxial failure mode of mixture M1 (consolidation stresses of $\sigma^{\prime}{ }_{\mathrm{v} 0}=150 \mathrm{kPa}$ and $\sigma^{\prime}{ }_{\mathrm{H} 0}=75 \mathrm{kPa}$ )

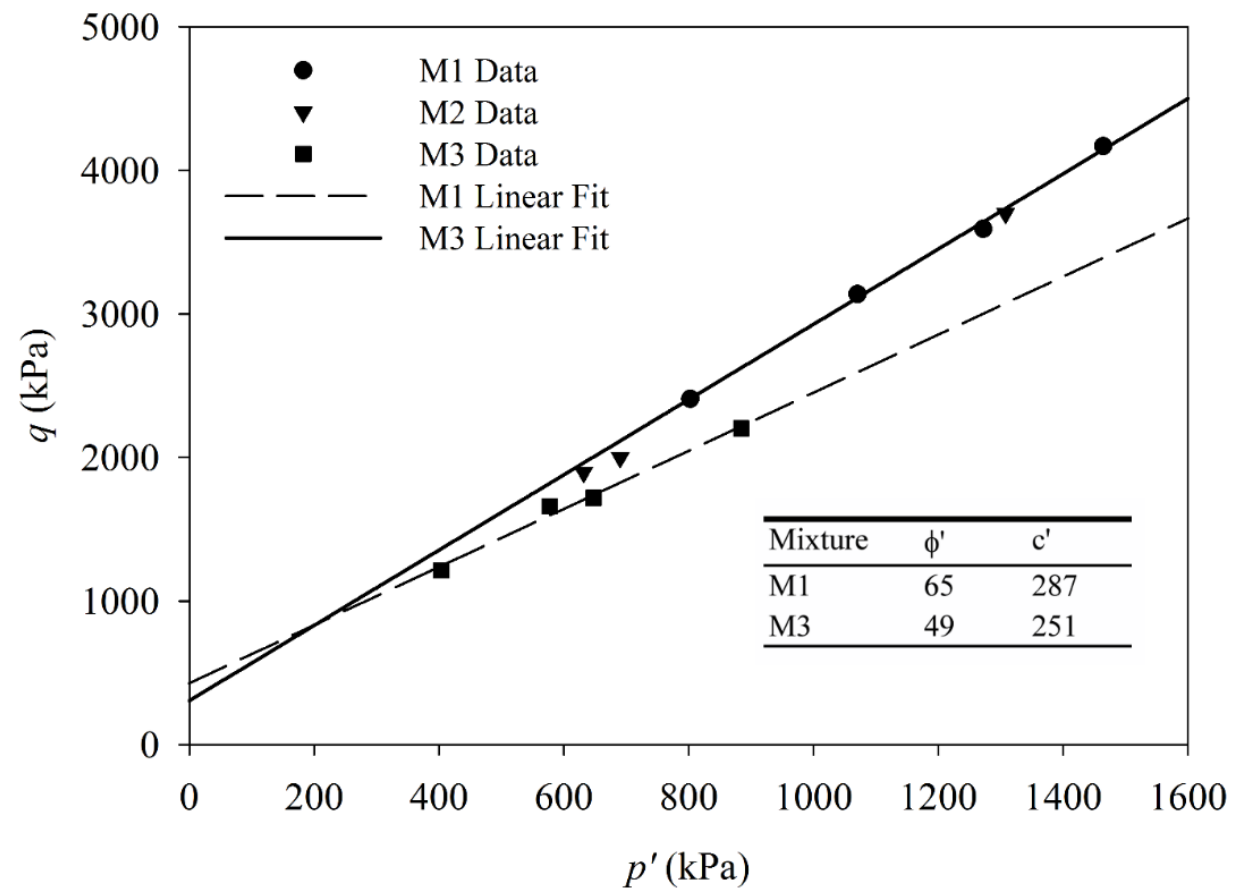

Figure 9: M1 and M3 strength envelopes obtained from triaxial compression tests 

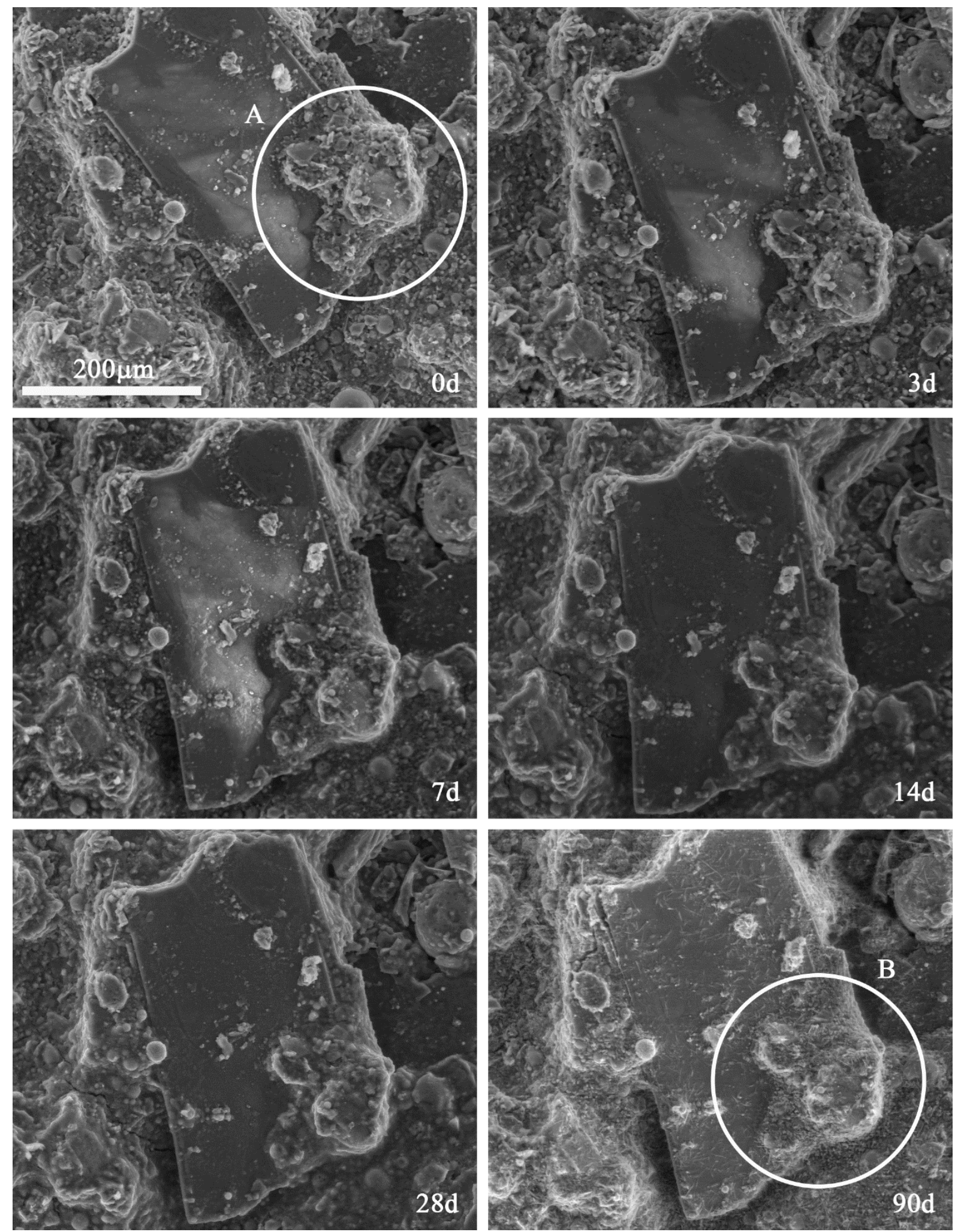

Figure 10: SEM micrographs of the M2 sample throughout the curing process 

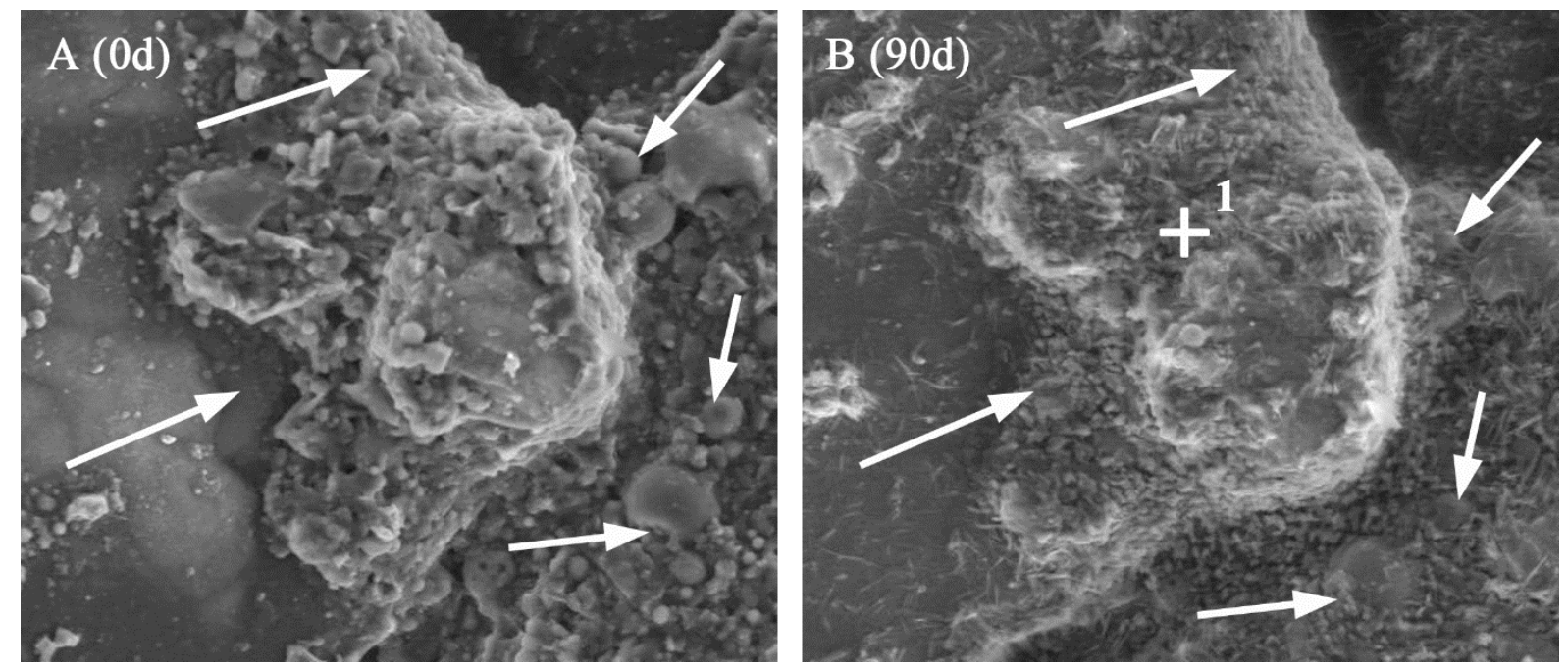

Figure 11: Examples of the modifications developed in the ash-activator paste at the instant of mixture preparation (A) and after curing for 90 days (B)

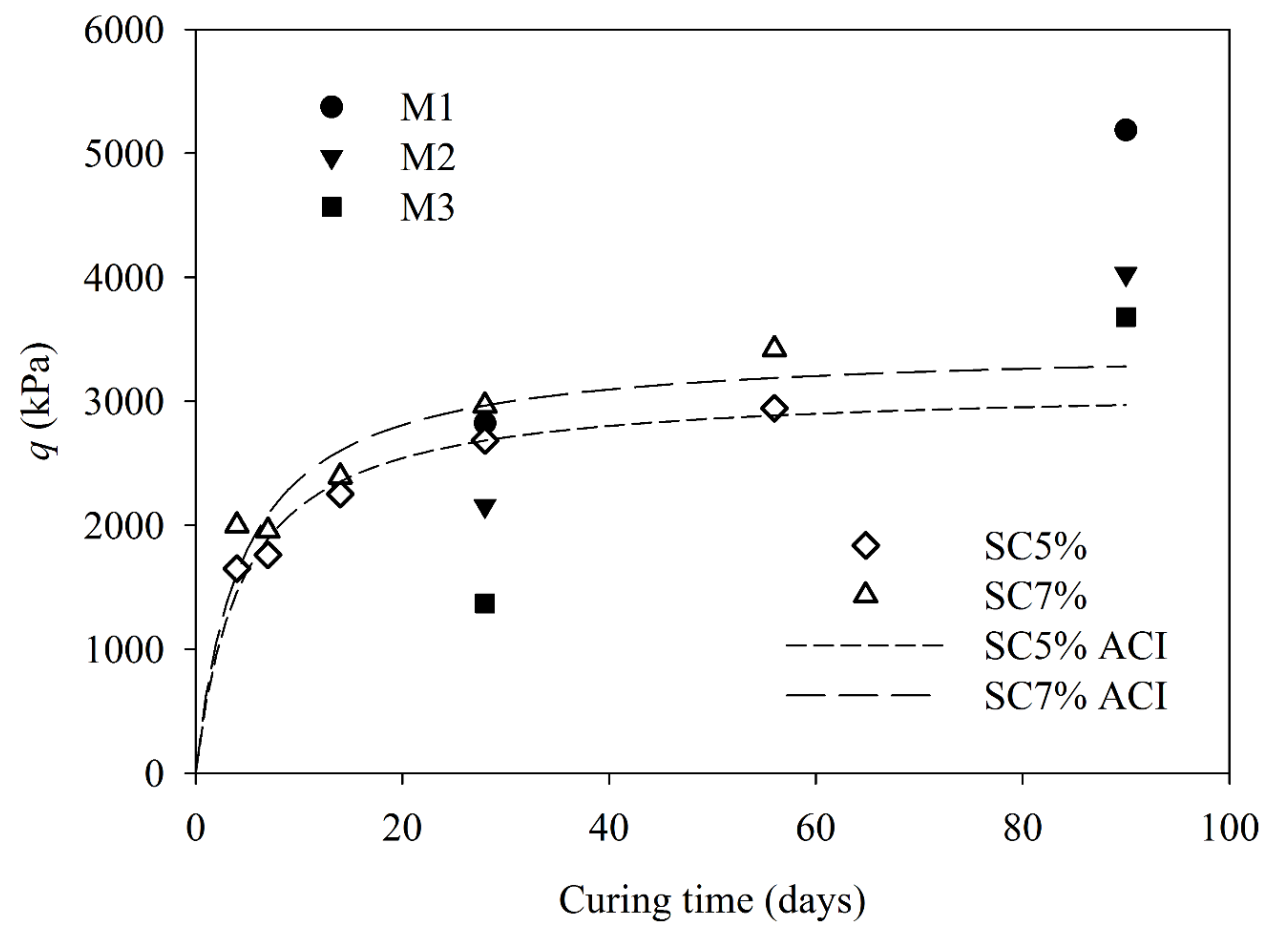

Figure 12: Comparison between the UCS data of the alkali activated and soil-cement mixtures 

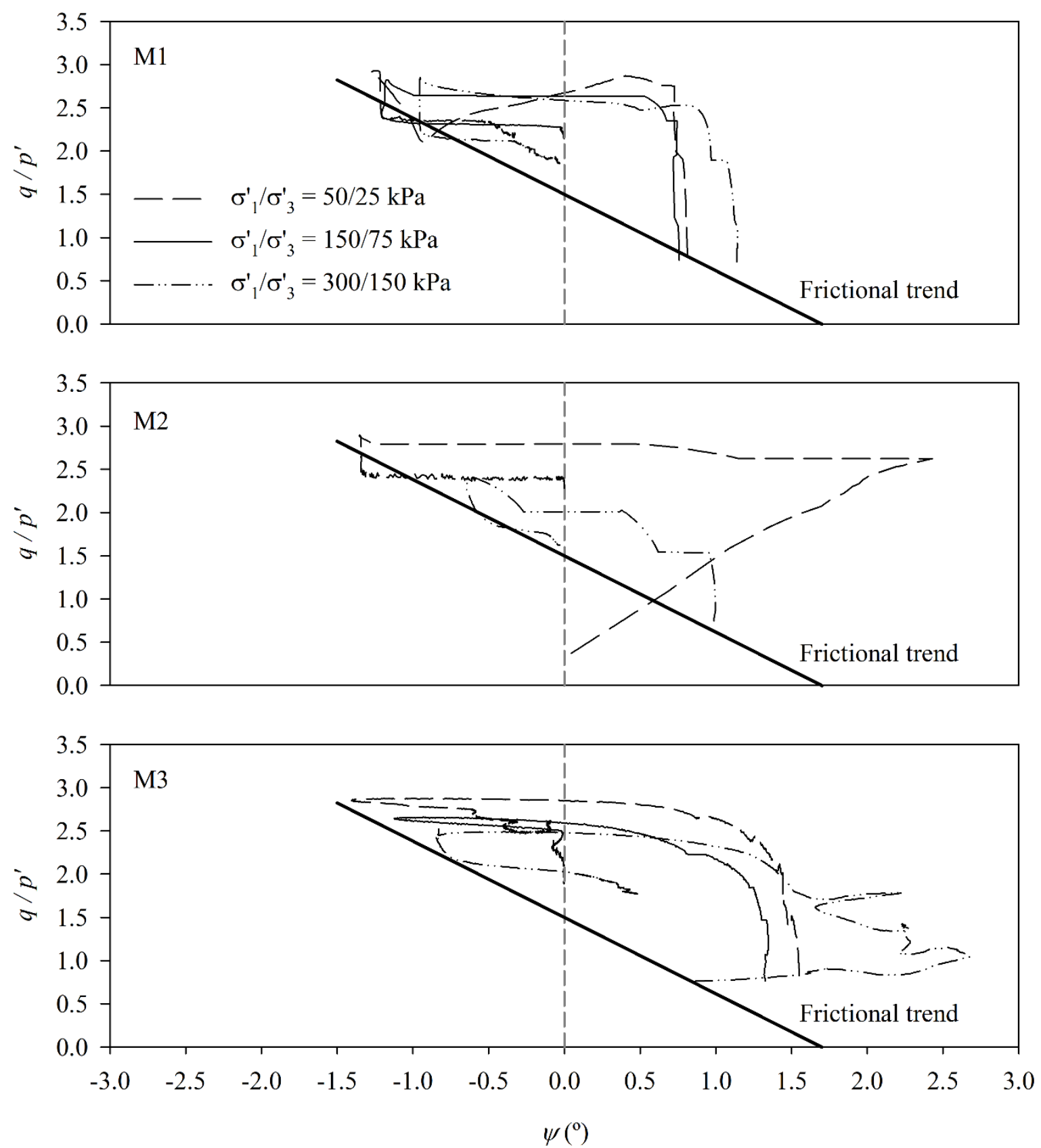

Figure 13: Stress-dilatancy response of the alkali activated mixtures 